Also it is almost essential that he should have worked in a cognate field of research, not as a mathematician.

The trouble is that scientific workers are never explicitly taught scientific method and argument. Even statistical teehniques are taught without this foundation, and, therefore, often degenerate into a modern Pythagorian mysticism. It is noteworthy that, in my experience, the best junior computors are, ceteris paribus, not science but librarianship students. The course for librarianship includes those essentials of logic and classification that are essential in the intelligent operation of computing schedules, calculating machines and strategic computing installations of the punched card and electronic type. (Use of highly trained scientific or mathematical workers for whole-time computation is a waste of valuable skill.)

Inasmuch as we train scientific men to answer questions but not to ask them, we cannot complain if strategical computors are described as 'electronic brains'. The interpretative mathematician, by devising machinery to answer questions, is, with his colleague the technologist who devises machinery to perform actions, making it possible for human beings to live like human beings, instead of like machines, especially in clerical activities. He needs no apology, but he does need opportunity and facilities.

R. A. FAIRThORNE

S.M.E. Computing Laboratory,

Royal Aircraft Establishment,

South Farnborough, Hants.

\section{Establishment of Cytochemical Techniques}

Is 1936 there appeared an admirable book "Histochemie Animale", by L. Lison. In this book, Lison tried to teach chemistry to the histologists, and by the weight of his own reasoning he was forced to discard a great many time-honoured histological methods the validity of which had never been really investigated. Recently, in an article entitled "Establishment of Cytochemical Techniques"1, J. F. Danielli endeavours to do a similar thing for cytochemistry, and, since some of his criticisms concern techniques which form the backbone of modern cytochemistry, it might, perhaps, be feared that his remarks will leave the cytochemist with a gloomy feeling of being suspended in mid-air without any reliable method to cling to. There is no doubt, however, that Dr. Danielli's plea for more exactness in eytochemistry is necessary and justified, and it is to be hoped that his article will have the same wholesome effect as Lison's book.

One of the points raised by Dr. Danielli concerns a technique which has been used at the Carlsberg Laboratory, and I should therefore like to add a few clarifying remarks. The principle involved is to stratify a cell by centrifugation, divide it and examine "the distribution of substances in the various fragments so obtained". This we have done in several crises $^{2,3}$, and we still believe that the conclusions drawn from these experiments are valid. Danielli's example of the untrustworthiness of the method concerns a case in which the respiration of the halves of sea-urchin eggs added up to more than the respiration of the intact egg. This, however, is concerned with the distribution of respiratory activity, and $K$. Linderstrom-Lang and I have, for the very reason illustrated by this example, repeatedly stressed ${ }^{4,5}$ the fact that the only conclusions to be drawn from experiments of this type are those based on the quantitative distribution of substances. In the case of an enzyme, as in our peptidase experiments, it is therefore necessary to kill the cell fragments, to remove diffusion difficulties by thorough cytolysis, to make sure of free contact between enzyme and substrate under conditions which are standardized for the enzyme determination, and to check that under these conditions the amount of enzyme found in the halves adds up to the value for the whole egg. If these provisions are made, we think that deductions are justified; but such deductions permit, of course, only indirect conclusions with regard to physiological activity.

Carlsberg Laboratory, Copenhagen.

${ }^{1}$ Danielli, J. F., Nature, 157, 755 (1946).

'Philipson, T., Compt. rend. Lab. Carlsberg, 20, No. 4 (1933).

' Holter, H., J. Cell. and Comp. Physiol., 8, 179 (1936).

- Linderstrom-Lang, K., Compt. rend. Lab. Carlsberg, 19, No. 13 (1932) sinderstrom-Lang, K., and Holter, H., Ergeb. der Enzymforsch. 3, 309 (1934) (see p. 311).

IT is most pleasing to read Dr. Holter's firm restatement of the basic principles which he and his colleagues at the Carlsberg Laboratory regard as essential in cytochemical studies by 'stratification' methods. We are completely in agreement on these points.

Most of the correspondence which has reached me on this matter has expressed agreement with the emphasis which I placed on the need for caution. Of the few dissentients, none has complained of feeling "suspended in mid-air"; nevertheless, I continue to hope that their position will ultimately become plain to them.

Chester Beatty Research Institute,

J. F. DANIELILI

Fulham Road,

London, S.W.3.

\section{Effect of Pressure on Crystal Growth}

I HAVE been greatly interested in the comments arising from my suggestion that the expansion of setting plaster-of-Paris might be due to the pressure exerted by crystals of gypsum growing non-isotropically in a not completely confined space ${ }^{1}$. The original suggestion was speculative, and it was made elear that it had no direct experimental confirmation. Undoubtedly, more direct proof would be required before it is accepted. But in pure water or in solutions of accelerators, in which expansion is greatest, the rate of growth parallel to the $c$-axis is some $10-20$ times greater than that perpendicular to the $c$-axis, and a considerable relative increase in solubility would be required to make the rate of growth parallel to the $c$-axis negligible compared with that perpendicular to it. It is not possible to express this in quantitative terms, or translate it into a force; but while experimental proof is lacking, the suggestion cannot be dismissed a priori, and is at least a possible explanation of a phenomenon for which no reasonable alternative is available.

I.C.I. (Billingham Division), Ltd.

F. R. HIMsworth Billingham.

1 Nature, 158, 13, 584 (1946) 